\title{
減圧下に拈ける二成分系の気液平衡*
}

伊東哲 生*

1. 緒宮

工業的に応く応用されている减圧䓠溜の目的とすると ころは，主として慜溜装置内の压力を堿ずることによっ て票溜せんとする物質の沸とう温度を下け゚てその物質が 重合したり就分解を起すことのない様な温度のるとで蒸 溜を行な扣うとするにある。沸とう温度を下け゚て蔗溜を 行なわんとする他の一つの工業的操作湟水蒸気蒸溜があ るが，溜出物が多少水に溶ける場合や温度を可成り下げ る必要のある時は，減压蒸溜瀬ることになる。また， 一般に共沸点は蒸留圧力を変えるとそれに従って移動す るがこの様な系炕対しては，適当な圧力を選定してやれ ば有利な蒸溜を行なうことができ，場合によっては共沸 を消すことも可能である。

堿圧下に括ける非理想溶液系の気液平衡関係を, 例兄 ばその系の常正のデータから推算することは，現在のと ころ未だ極めて不充分である。しかるに後述する如く， 減圧下における二成分系の気液平衡関係を実測したデー 夕は意外飞少く，文献の数で 60 余り，采の数で 80 余り, さらに, 1935 年以前に発表されている一般にあまり信頼 できないといわれる文献28 まで含めても，せいせい系 の数で 120〜130程度と思われる。

以下，减压下に批引る成分系の気液平衡についてそ の熱力学的な考察を行ない，推算方法の一端を述へ，さ らに現在までに発表されている文献の要旨を表示して参 考に供したいと思う。

\section{2. 熱力学的考察}

一般に我々が取扱う多くの溶液は非理想溶液であって

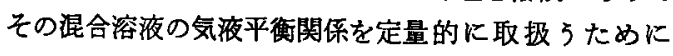
は，活量および活量係数を考えるのが便利である。

$i$ 成分の活量 $a_{i}$ は，その成分の与えられた状態にお ける逃散能と，それと同一温度におけるある標準状態の 同一成分の逃散能の比であり

$$
a_{i}=\frac{f_{i}}{f_{i}^{0}}
$$

で示される。

化学ポテンシャル $\mu_{i}$ は Lewisにより次の如く定義さ れている。

\footnotetext{
* 昭和 35 年 6 月 6 日受理

**花王石㻌株式会社技術開発部
}

$$
\mu_{i}=R T \ln f_{i}+B(T)
$$

$B(T)$ は䆅分定数で温度のみの函数である。

(1) および (2) 式より次の関係が得られる。

$$
\mu_{i}-\mu_{i}{ }^{0}=R T \ln \frac{f_{i}}{f_{i}{ }^{0}}=R T \ln a_{i}
$$

すなわち，活量はその状態における化学ポテンシャル と標準状態における化学ポテンシャルとの差から求める ことができる。標隼状態としては一般に系の温度および 圧力に拈ける純成分の状態を選よ゙。したがって純成分の 活量は常に】である。理想溶液系における $i$ 成分の逃散 能はそのモル分率 $x_{i}$ に比例し且つ比例係数は $f_{i}{ }^{0}$ に等し いから

となる。

$$
f_{i}=f_{i}^{0} x_{i}
$$

活量係数 $r_{i}$ は次の如く定義される。

$$
\gamma_{i}=\frac{a_{i}}{x_{i}}
$$

したがって，理想溶液系においては $\gamma_{2}=1$ となる。

(1) 式を（5）式に代入して

$$
r_{i}=\frac{f_{i}}{x_{i} f_{i}^{0}}
$$

1 気圧付近の比較的低圧なる条件下においては，気相 は概ね理想気体とみなすことができて，Dalton の法則 を仮定して（6）式は次の如くなる。

$$
r_{i}=\frac{p_{i}}{x_{i} P_{i}^{0}}=-\frac{y_{i} P}{x_{i} P_{i}{ }^{0}}
$$

（7）式から $r_{i}$ はまた， Raoult の法則からの偏異因子 であることがわかる。

さて，気液平衡関俰が減压することによっていかに变 化するであろ5かを熱力学的に導くためには，活量また は活量係数の変数による变化量を求めればよい。

濃度一定なる条件下では活量または活量保数におよぼ す圧力自体の影䇾は一般に小さく，したがって圧力変化 に伴な5平衡温度变化がそれらに执よぼす影䈏のみを考 えれば充分である。

(3) 式を書さなおすと

$$
\ln a_{i}=\frac{1}{R}\left(\frac{\mu_{i}}{T}-\frac{\mu_{i}{ }^{0}}{T}\right)
$$

$i$ 成分の化学ポテンシャルはその成分のモル増加当り の自由エネルギー增加であるから 


$$
\mu_{i}=\left(\frac{\partial G}{\partial n_{i}}\right)_{T, P, n_{j \neq i}}
$$

また

$d G=\left(\begin{array}{c}\partial G \\ \partial T\end{array}\right)_{P, n_{1}, n_{2} \cdots \cdots n_{k}} d T+\left(\frac{\partial G}{\partial P}\right)_{T, n_{1}, n_{2} \cdots \cdots n_{k}} d P$

熟力学の第一および第二法則から

$$
d G=-S d T+V d P
$$

したがって

$$
\begin{aligned}
& \left(\begin{array}{l}
\partial G \\
\partial T
\end{array}\right)_{P, n_{1}, n_{2} \cdots \cdots n_{k}}=-S \\
& \left(\begin{array}{c}
\partial G \\
\partial P
\end{array}\right)_{T, n_{1}, n_{2} \cdots \cdots n_{k}}=V
\end{aligned}
$$

(9)拈よび（12）式から

$$
\frac{\partial \mu_{i}}{\partial T}=\begin{array}{cc}
\partial & \partial G \\
\partial T & \partial n_{i}
\end{array}=\frac{\partial}{\partial n_{i}} \frac{\partial G}{\partial T}=-\frac{\partial S}{\partial n_{i}}=-\bar{S}_{i}
$$

$\bar{S}_{i}$ は $i$ 成分の分子配エントロピーである。従って

$$
\begin{aligned}
\frac{\partial\left(\mu_{i} / T\right)}{\partial T} & =\frac{1}{T^{2}}\left(-\mu_{i}+T-\frac{\partial \mu_{i}}{\partial T}\right) \\
& =\frac{1}{T^{2}}\left\{\frac{\partial}{\partial n_{i}}(-G-T S)\right\} \\
& =-\frac{1}{T^{2}} \frac{\partial H}{\partial n_{i}}=-\begin{array}{l}
\bar{H}_{i} \\
T^{2}
\end{array}
\end{aligned}
$$

$\bar{H}_{i}$ は $i$ 成分の分子配エンタルピーである。

（15）式を考えながら（8）式を温度で微分すれば

$$
\begin{aligned}
& \left(\begin{array}{c}
\partial \ln a_{i} \\
\partial T
\end{array}\right)_{P, x}=\frac{1}{R}\left\{\begin{array}{c}
\partial \\
\partial T
\end{array}\left(\frac{\mu_{i}}{T}-\frac{\mu_{i}{ }^{0}}{T}\right)\right\}_{P, x} \\
& =-\frac{\bar{H}_{i}-H_{i}{ }^{0}}{R T^{2}}
\end{aligned}
$$

（16）式は結局,（5）式を考えながら

$$
\left(\frac{\partial \ln \gamma_{i}}{\partial T}\right)_{P, x}=-\frac{\bar{H}_{i}-H_{i}{ }^{0}}{R T^{2}}=-\begin{gathered}
L_{i} \\
R T^{2}
\end{gathered}
$$

となる。たたし， $L_{i}=\bar{H}_{i}-H_{i}{ }^{0}$ は $i$ 成分の溶液中にお ける分子配エンタルピーから同一温度に拈けるその純成 分の液のエンタルピーを差引いた值である。すなわち $L_{i}$ は無限量の溶液に $i$ 成分の 1 モルを加えた時に系が吸収 する熱量と考えることができ，一般に混合熱と呼ばれる ஆのである。

(17）式から次のことが明らかである。すなわち， $L_{i}$ が正つまり混合により吸熱する系においては温度が上昇 するほど $\gamma_{i}$ は小さくなり，その極限では $\gamma_{i}=1$ であ る。したがって，この様な系では $\gamma_{i}$ は常に1より大き い。逆に， $L_{i}$ が負つまり混合により発熱する系において は温度か上年するほど $\gamma_{i}$ は大きくなり，その極限は同 様に $\gamma_{i}=1$ である。したがってこの様な系では $r_{i}$ は 常に1より小さい。

しかしながら水溶液に対しては以上の如く簡単に考え ることができない場合がある。なぜならば，その温度变
化範围内においてしばしば $L_{i}$ の符号が変ることがある からである。以上の考察から，特別な例を除けば混合に 上り吸熱する系む発熱する系もともに减圧するほど $\gamma_{i}$ は1から離れていく。つまり，Raoult の法則からの偏 異は一層大きくなることを意味する。

温度および王力一定のもとにおいて，活量俰数におよ ぼす濃度の影響を表す式としてはvan Laar の式, Margules の式などがあるが，例えば二成分系に対する van Laar の式は次式の形で表すのが普通である。

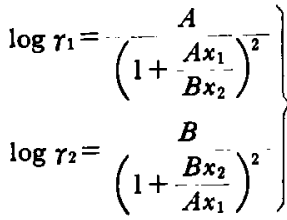

$A$ およびB はその系と状態に特有な定数である。van Laar の式は元来温度一定の条件下で導かれた式である が，二成分の沸点差がまり大きくない場合には圧力一 定の条件下に批る気液平衡関係をるよく表わし得る。

（18）式の性質より

$$
\left.\begin{array}{l}
A=\left(\log r_{1}\right)_{x_{1}=0} \\
B=\left(\log r_{2}\right)_{x_{1}=1}
\end{array}\right\}
$$

であるからこの場合の（17）式は次の如くなる。

$$
\left.\begin{array}{l}
\frac{d A}{d T}=-\frac{L_{1}{ }^{0}}{2.303 R T^{2}{ }_{x_{1}=1}} \\
\frac{d B}{d T}=-\frac{L_{2}{ }^{0}}{2.303 R T^{2}{ }_{x_{1}=0}}
\end{array}\right\}
$$

$L_{1}{ }^{0}$ は無限量の第 2 成分液に第 1 成分の 1 モルを， $L_{2}{ }^{0}$ は無限量の第 1 成分液に第 2 成分液の 1 モルを加えた時 の混合熱であって，一般に無限稀釈度における混合熱と 呼ばれるむのである。van Laar の式が当てはまる系に 対しては，(17）式の代りに（20）式を使って例えば常 王下のデータをるとにして求めんとする现力下に拈ける $A$ および $B$ を計算すれば，中間の各濃度による活量係 数变化を計算する労をはふくくことができる。

例えば常珐下におけるデータをるとにしておる珐力下 に拈ける気液平衡関係を推算するに当って，(17)式を適 用する場合には各温度および濃度における混合熱のデー タが（20）式を使う場合には各温度における無限稀釈度 の混合熱のデータが必要である。しかしながら実際には 混合熱に関するデータはその数が極めて少なく，且つ不 正確で，またその大部分は常温付近の測定值である。

混合熱は一般に温度により变化し，特に非理想系にお いてはその栾化は著しく大きい。したがって，(17）式 または（20）式を使ってある全王下における気液平衡関 係をある程度正確に推算することは一般に困難である。 
$L_{1}{ }^{0}$ おむひ $L_{2}{ }^{0}$ が温度により変化しないとみなすこと ができる場合には（20）式を積分して

$$
\left.\begin{array}{l}
A=\frac{L_{1}{ }^{0}}{2.303 R T}=\text { const. } \times \frac{1}{T} \\
B=\frac{L_{2}{ }^{0}}{2.303 R T}=\text { const. } \times \frac{1}{T}
\end{array}\right\}
$$

となり, $A T$ 打よび $B T$ の值が常沉一定であることに なる。

さて, 以上の結果 $x-y$ 曲線が減圧によってどの様に 変っていくかを次に述へる。いま，一般の理想気体を形 成する二成分采炕ついて考えると両成分の揮発度は

$$
\begin{aligned}
& v_{1}=\frac{y_{1}}{x_{1}}=\frac{\gamma_{1} P_{1}{ }^{0}}{P} \\
& v_{2}=\frac{y_{2}}{x_{2}}=\frac{\gamma_{2} P_{2}{ }^{0}}{P}
\end{aligned}
$$

したがって第二成分に対する第一成分の比揮発度は

$$
\alpha={ }_{v_{2}}^{v_{1}}=\frac{x_{2} y_{1}}{x_{1} y_{2}}=\frac{\gamma_{1} P_{1}{ }^{0}}{\gamma_{2} P_{2}{ }^{0}}
$$

（24）式から判る通り，比揮度の增大は $y_{1}>x_{1}$ の時は $x-y$ 曲線が脹らむことを意味する。もちろん，減王にし ていくと一概に $x-y$ 曲線が脹れるとは限らない。要は, （24）式の值を各殴力で計算し比揮発度が減圧により大 きくなれば脹れ，小さくなれば脹らみは小さくなり，不 变であればあた $x-y$ 曲線す不変である。ある濃度に打け る $\gamma_{1} / \gamma_{2}$ の值の圧力に上る变化が $P_{1}{ }^{0} / P_{2}{ }^{0}$ のそ机に比し 小さいよらな系に対しては, 各圧力に拉ける $P_{1}{ }^{0} / P_{2}{ }^{0}$ の 值を比較することによって王力変化に伴なら $x-y$ 曲線の 変化の傾向を定性的に知ることができる。このよな系 に対しては，一般に同族系同士の平衡関係は堿圧すると $x-y$ 曲線の脹らみが增して苏溜が容易になるであるうこ とは Cox 線図の上から考えることができる。

\section{3. 推 策 法}

以上は堿王下に批ける成分系の気体平衡について熱 力学的な考察を行なったが，実際には次の如き順序で決 定ないしは推算することが望ましい。ます，その系の減 欧下における実測値が発表されているかどうかを第 1 表 および文献 ${ }^{28}$ について調でる。熱力学的な検討を行なっ た結果，それが信頼できる実測值であれば採用すべは るちろんである。また，圧力によって実測值を内括する こともでる。次に減圧下に批ける実測值が発表されて
おらず，常生下のデータのみしか得られないときはこ のデータを(7)式に代入して活量保数を求め，これを液 漶度に対して点緅し van Laar の式などが適用できるか 否かを確める。適用できる場合には（20）式によって求

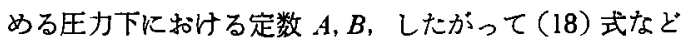
により活量係数を推算することができ，さらに（7）式に よって $x_{i}$ に対する $y_{i}$ を求めることができる。混合熱の データがない場合には（21）式を使って推算してもその 結果にはさほど大きい誤差を生するることはない。van Laar の式などが適用できない系に対しては（17）式に よって各浱度に扣ける活量係数の圧力による变化值を求 めることができる。この場合す，混合熱のデータがない 場合には(21)式と同じ考え方て推算することができる。 求めんとする圧力下に括ける平衡温度を推定するにはま す Cox 線罒の上で純成分の蒸気压を示す二直線の間に 各濃度の液の蒸気圧を示寸直線を常圧下の平衡温度をむ とにして引きそれらの線上から読みとることができる。

共沸をつくる系に批いて，その共沸点が圧力によって どの様に移動するであろらかは上述の手段を経ずとす次 の如くして推定することができる。すなわち，例えば正 の共沸をつくる系について考劣れば，共沸点のデータを Cox 線罒の上に点経すると一つの直線が得られる。この 場合，共沸温度は両成分のどの沸点よりも低いから共沸 点を示す直線は両成分のどの直線よりる上になる。共沸 点を示す直楾を延長してついにどちらかの成分の線を切 るに相当する圧力のるとでは，共沸点が丁度消えること になる。共沸データが一つしかないときはその点を通り 両成分の直線の勾配を平均した勾配の直線を引けば，共 沸点が消えるであろら大体の王力を求めることができ る。しかし，例外る多いから注意を要する。負の共沸に 対しても全く同様に考えることができる。

\section{4. 既往の測定テータ}

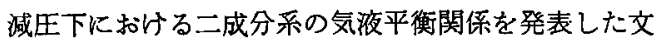
献のほとんどについてその要旨を第 1 表に表示する。測 定に使用した平衡装固は Othmer 型が最も多く全体の $45 \%$, Colburn 型 21\%, Gillespie 型 10\%などである が，最近ではその他の新しい装置型式による測定結果が 多く発表される様になっている。なお，わが国では未だ 発表された例がない。 
第 1 表 減圧下に拈ける二成分系の気液平衡交献要旨

\begin{tabular}{|c|c|c|c|c|c|}
\hline 低沸成分 & 高沰 成 分 & 平衡匠力 $[\mathrm{mm} \mathrm{Hg}]$ & 温 度 $\left[{ }^{\circ} \mathrm{C}\right]$ & 装贯型式 & 文献 \\
\hline acet aldehyde & ethyl alcohol & $77,398,699$ & & & 17) \\
\hline acetic acid & $\begin{array}{l}\text { 2,3-buthylene glycol } \\
\text { diacetate }\end{array}$ & $150,300,500,760$ & $75 \sim 191$ & Othmer & 44) \\
\hline acetone & water & $200,350,500,760$ & $22 \sim 100$ & Othmer & 41) \\
\hline$"$ & carbon tetrachloride & $300,450,760$ & $31 \sim 77$ & Othmer & 3) \\
\hline$"$ & cumene & $100,340,425,758$ & & & 48) \\
\hline$"$ & methyl alcohol & & & & 55) \\
\hline$"$ & $"$ & 100 & $7 \sim 18$ & Othmer & 21) \\
\hline$"$ & $"$ & $200,747,11090$ & $22 \sim 160$ & & 8) \\
\hline acetonitrile & water & $150,300,760$ & $36 \sim 100$ & Othmer & 42) \\
\hline aniline & nitrobenzene & & & & 27) \\
\hline benzene & aniline & 350,760 & & Reinders 改良型 & 34) \\
\hline$"$ & $n$-heptane & $300,400,500,600,700,760$ & $53 \sim 98$ & Scatchard 改良型 & 54) \\
\hline$"$ & $"$ & 180,400 & $39 \sim 68$ & Braun & 40) \\
\hline n-buthyl alcohol & buthyl acetate & $50,165.5,760$ & & & 53) \\
\hline sec-buthyl alcohol & methyl ethyl ketone & $374.5,760$ & $60 \sim 100$ & Colburn 改良型 & 2) \\
\hline 2,3-buthylene glycol & $\begin{array}{l}\text { 2,3-buthylene glycol } \\
\text { diacetate }\end{array}$ & $250,350,500,760$ & $145 \sim 193$ & Othmer & 44) \\
\hline caproic acid & caprylic acid & $2,10,50$ & & Rose-Williams & 1) \\
\hline$"$ & $"$ & $20,50,100$ & $111 \sim 175$ & Rose-Williams & 50) \\
\hline chlorobenzene & ethyl benzene & $20,300,760$ & & Othmer & 25) \\
\hline chloroform & methyl alcohol & $400,500,600$ & & & 39) \\
\hline p-cresol & benzidine & 100 & & & 52) \\
\hline cyclohexane & aniline & 350,760 & & Reinders 改良型 & 34) \\
\hline n-decane & $t$-decalin & $\begin{array}{l}50,100,150,180,200,250, \\
300,400,720,740\end{array}$ & & Othmer 二基立 & 20) \\
\hline$"$ & $"$ & $10 \sim 100$ & & & 16) \\
\hline$"$ & $"$ & $10,20,50$ & $56 \sim 95$ & Othmer & 56) \\
\hline$"$ & $"$ & $10,20,50,100,760$ & & Othmer & 65) \\
\hline decanol & dodecanol & $20,50,100.300$ & $131 \sim 220$ & Rose-Williams & 51) \\
\hline dodecane & hexadecene & $10,20,50,100,200,400,760$ & $90 \sim 285$ & Colburn & 33) \\
\hline$"$ & 1-octadecene & $10,20,50,100,200,400,760$ & $93 \sim 300$ & Colburn & 31) \\
\hline ethyl alcohol & benzene & 180,400 & $32 \sim 63$ & Braun & 40) \\
\hline$"$ & $n$-heptane & $180,400,760$ & $38 \sim 90$ & Gillespie & 32) \\
\hline$"$ & water & $95,190,380,760$ & $35 \sim 85$ & Baker 改良型 & 5) \\
\hline$n$ & $"$ & 95 & & Othmer & 56) \\
\hline ethyl benzene & styrene & 100 & & $\begin{array}{l}\text { Jones-Schoenborn } \\
\text { column still } \\
\text { 改良型 }\end{array}$ & 60) \\
\hline$"$ & $"$ & $10,20,50,100,200$ & $26 \sim 97$ & Colburn & 12) \\
\hline ethyl phenyl acetate & ethyl $\alpha$-phenyl butyrate & $47.5,95,190,380$ & $138 \sim 213$ & Othmer & 4) \\
\hline formic acid & dimethyl formamide & 100 & & & 35) \\
\hline furfural & furfuryl alcohol & 25 & $64 \sim 84$ & Othmer 改良型 & 18) \\
\hline$"$ & $"$ & 25 & $68 \sim 85$ & Colburn & 63) \\
\hline heptane & ethyl benzene & $100,300,760$ & & Braun & 38) \\
\hline$n$-hexadecane & n-hepthyl benzoate & $1,3.5,15$ & $105 \sim 165$ & Othmer & 65) \\
\hline n-hexane & methyl cyclopentane & $200,400,600,760$ & $31 \sim 72$ & Braun & 19) \\
\hline$"$ & toluene & $150,300,760$ & & Braun & 38) \\
\hline lauric acid & mylistic acid & 4 & $154 \sim 174$ & Gillespie & 61) \\
\hline 2,6-lutidine & phenol & $200,400,600,760$ & $100 \sim 182$ & Othmer & 43) \\
\hline methyl alcohol & methyl ethyl ketone & $\begin{array}{l}100,275,757,2040,4630 \text {. } \\
11090\end{array}$ & $18 \sim 200$ & & 8) \\
\hline$n$ & methyl propyl ketone & $100,747,5400$ & $35 \sim 185$ & & 8) \\
\hline$"$ & water & $200,350,500,760$ & $35 \sim 93$ & Othmer & 41) \\
\hline 2-methoxyl ethyl alcohol & water & 100,752 & & & 30) \\
\hline methyl cyclohexane & toluene & 200,400 & $60 \sim 90$ & Othmer & 59) \\
\hline methyl ethyl ketone & water & $200,350,500,760$ & $40 \sim 100$ & Othmer & 41) \\
\hline methyl palmitate & methyl stearate & 4 & & & 37) \\
\hline mylistic acid & polmitic acid & 4 & $174 \sim 192$ & Gillespie & 61) \\
\hline naphthalene & 1-hexadecene & 200 & $169 \sim 224$ & Colburn 大型 & 35) \\
\hline$"$ & 1-octadecene & $10,20,50,100,200,400,760$ & $90 \sim 300$ & Colburn 改良型 & 36) \\
\hline$"$ & $n$-tetradecane & $10,20,50,100,200,400,760$ & $85 \sim 250$ & Colburn 改良型 & 26) \\
\hline$"$ & $"$ & 200 & $168 \sim 172$ & Colburn 大型 & 58) \\
\hline$o$-nitro ethyl benzene & $p$-nitro ethyl benzene & 100 & & & 57) \\
\hline nitro methane & nitro ethane & $54.6,100,200,400$ & $34 \sim 91$ & Gillespie 改良型 & 11) \\
\hline$n$-octane & ethyl benzene & $50,200,500,760$ & $50 \sim 135$ & Colburn & 64) \\
\hline 766 & & (42) & & 化 学 & \\
\hline
\end{tabular}




\begin{tabular}{|c|c|}
\hline 低沸成分 & 高沸成分 \\
\hline octanol & decanol \\
\hline palmitic acid & stearic acid \\
\hline phenol & cumene \\
\hline$\beta$-picoline & phenol \\
\hline$r$-picoline & $"$ \\
\hline$a$-pinene & $\beta$-pinene \\
\hline 2-propyl alcohol & water \\
\hline tetra decane & 1-hexadecene \\
\hline$n$ & '" \\
\hline toluene & $n$-octane \\
\hline $\begin{array}{l}\text { 2,6-toluene diisocyanate } \\
\text { trichloroethylene } \\
\text { water }\end{array}$ & $\begin{array}{l}\text { 2,4-toluene disocyanate } \\
\text { tetrachloroethylene } \\
\text { acetic acid }\end{array}$ \\
\hline$"$ & " \\
\hline$"$ & $"$ \\
\hline$"$ & $"$ \\
\hline$"$ & 2,3-butylene glycol \\
\hline$"$ & $"$ \\
\hline$"$ & diacetone alcohol \\
\hline$"$ & formic acid \\
\hline$"$ & $"$ \\
\hline$"$ & $"$ \\
\hline$"$ & hydrazine \\
\hline$"$ & phenol \\
\hline$"$ & propionic acid \\
\hline
\end{tabular}

\begin{tabular}{|c|c|c|c|}
\hline 平衙压力 $[\mathrm{mm} \mathrm{Hg}]$ & 温度 $\left[{ }^{\circ} \mathrm{C}\right]$ & 装埴型式 & 交 \\
\hline $20,50,100,300$ & $104 \sim 187$ & Rose-Williams & 51) \\
\hline 4 & $192 \sim 209$ & Gillespie & 61) \\
\hline $200,400,600,760$ & $100 \sim 182$ & Othmer & 43) \\
\hline $\begin{array}{l}200,400,600,760 \\
15,30,55\end{array}$ & $103 \sim 187$ & Othmer & $\begin{array}{r}\text { 43) } \\
9 \text { ) }\end{array}$ \\
\hline $95,190,380,760,3087$ & $38 \sim 120$ & Othmer & 62) \\
\hline $10,20,50,100,200,400,760$ & $124 \sim 271$ & Colburn & 46) \\
\hline & $204 \sim 229$ & Colburn 大型 & 58) \\
\hline $\begin{array}{l}20,50,100,200,300,400, \\
640.760\end{array}$ & & Othmer & \\
\hline $5,30,60$ & $10 \sim 165$ & Othmer & 15) \\
\hline $190,380,760$ & $47 \sim 121$ & Othmer & 4) \\
\hline $125,250,500,760$ & $56 \sim 118$ & Othmer & 22) \\
\hline $20,70,200,760,2053,5931$ & $22 \sim 243$ & & $\begin{array}{l}\text { 45) } \\
\text { 48) }\end{array}$ \\
\hline $70,200,760$ & $45 \sim 118$ & Braun & 29) \\
\hline $127 \pm 5,750 \pm 5,2.11,4.57 \mathrm{~atm}$ & $58 \sim 172$ & Othmer & 7) \\
\hline $200,350,500,760$ & $67 \sim 172$ & Othmer & 44) \\
\hline $50,100,200,400,760$ & $38 \sim 110$ & Colburn 改良型 & 23) \\
\hline $50,100,200,760$ & & Gillespie & 13) \\
\hline $50,100,200$ & & & 3) \\
\hline $70,200,760$ & $35 \sim 108$ & Braun & 29) \\
\hline $\begin{array}{l}124.8,281.8,411.2,560.4 \text {, } \\
700.6\end{array}$ & $56 \sim 112$ & $\begin{array}{l}\text { Sameshi } \\
\text { COthm }\end{array}$ & 10) \\
\hline 40,2 & & 分泊 & 17) \\
\hline $70,200,760$ & $45 \sim 140$ & Braun & 29 \\
\hline
\end{tabular}

\begin{tabular}{|c|c|c|}
\hline & 号 & \\
\hline$a ：$ 活量 & $P:$ 圧力 & $T:$ 温度 \\
\hline$A$ : van Laar の式の定数 & $P^{0}:$ 純成分の蒸気圧 & $x$ ：液相におけるモル分率 \\
\hline$B: \quad " \prime$ & $R:$ 気体定数 & $y$ : 蒸気相にお汁るモル分率 \\
\hline$f$ : 逃散能 & $S:$ エントロピー & \\
\hline$f_{0}$ ：純成分の逃散能 & $\bar{S}$ ：分子配エントロピー & $\alpha:$ 比揮発度 \\
\hline$G:$ 自由エネルギー & $v ：$ 揮発度 & $r$ ：活量係数 \\
\hline$H$ : 分子エンタルピー & $V:$ 分子容積 & $\mu$ ：化学ポテンシャル \\
\hline $\bar{H}$ ：分子配×ンタルピー & $\bar{V}$ ：分子配容積 & \\
\hline
\end{tabular}

\section{文}

1) Acciarri, J. A. . M. S. Thesis. Penn. State Univ. (1954)

2) Amick, E. H., Weiss, M. A., Jr. and Kirshenbaum, M. S. . Ind. Eng. Chem., 43, 969 (1951)

3) Backman, K. C. and Simons, E. L. : Ind. Eng. Chem., 4L, 202 (1952)

4) Backman, K, C., Zimmerli, A. and Simons, E. L. . Ind. Eng. Chem., 42, 2569 (1950)

5) Beebe, A. H., Coulter, K. E. Jr., Lindsay, R. A. and Baker, E. M. . Ind. Eng. Chem., 34, 1501 (1942)

6) Berg. L. and Popavac. D. O. . Chem. Eng. Progr., 45, 683 (1949)

7) Blom, R. H., Mustakas, G. C., Efron, A. and Reed, D. L. : Ind. Eng. Chem., 37, 870 (1945)

8) Britton, E. C., Nutting, H. S. and Horsley, L. H. . Anal. Chem., 19, 601 (1947)

9) Bukala, M., Majewski, J. and Rodzinski, W. . Prze. mysl Chem., 9, 513 (1953)

10) Burtle, J. G: Ind. Eng. Chem., 14, 1675 (1952)

11) Cantoni, A. and Julian, F. . Ind. Eng. Chem., 45, 2580 (1953)

\section{献}

12) Chaiyavech, P. and van Winkle, M. J. Chem. Eng. Data, 4, 53 (1959)

13) Chalov, N. V. and Aleksandrova, O. A. Gidroliz. i Lesokhim. Prom., 10, No. 3, 15 (1957)

14) Chu, J. C. . "Distillation Equilibrium Data" (1950)

15) Cole, H. N. . Ind. Eng. Chem., Data Series, 3, 213 (1958)

16) Cusack, J. H. . Ph. D. Thesis. Penn. State Univ. (1954)

17) de Leeuw : Zeitshrift für Physikalishe Chemie, Stöchiometrie und Verwandtschaftslehre, 77, 284 (1911)

18) Dunlop, A. P. and Trimble, F. : Ind. Eng. Chem., 32, 1000 (1940)

19) Ehrett, W. E. and Weber, J. H. . J. Chem. Eng. Data. 4, 142 (1959)

20) Fenske, M. R., Myers, H. S. and Quiggle, D. : Ind. Eng. Chem., 42, 649 (1950)

21) Fordyce, C. R. and Simonsen, D. R. : Ind. Eng. Chem., 41, 104 (1949)

22) Gilmont, R. and Othmer, D. F. . Ind. Eng. Chem., 36, 1061 (1944)

23) Hack, C. W. and van Winkle, M. . Ind. Eng. Chem., 46. 2392 (1954) 
24) Hála, E., Pick, J., Fried, V. and Vilim, O. . "VapourLiquid Equilibrium" (1958)

25) Hawkins, J. E. and Brent, J. A. Jr. . Ind. Eng. Chem., 43, 2611 (1951)

26) Haynes, S. Jr. and van Winkle, M. . Ind. Eng. Chem., 46, 334 (1954)

27) Holtzlander, G. W. and Riggle, J. W. : A. I. Ch. E. J., 1, 312 (1955)

28) Horsley: "Azeotropic Data" (1952)

29）伊東：京大士論文 (1960)

30) Jakubicek, J., Fried, V. and Vahala, J. Chem. Listy, 51, $1422(1957)$

31) Jordan, B. T.. Jr. and van Winkle, M. : Ind. Eng. Chem., 43, 2908 (1951)

32) Katz, K. and Newman, M. : Ind. Eng. Chem., 48, 137 (1956)

33) Keistler, J. R. and van Winkle, M.: Ind. Eng. Chem., 44. 622 (1952)

34) Kortüm, G., Freier, H. J. and Woerner, F. Chem. Ing. Tech. 25, 125 (1953)

35) Maltese, P. and Valentini, G. . Chim. Ind. (Milan), 40,548 (1958)

36) Martin, W. L. and van Winkle, M. : Ind. Eng. Chem., 46, 1477 (1954)

37) Monick, J. A., Allen, H. D. and Marlies, C. J. J. Am. Oil Chemists' Soc., 23, 177 (1946)

38) Myers, H. S. . Ind. Eng. Chem., 47, 2215 (1955)

39) Natradze, A. G. and Novikova, K. E. . Zhur. Fiz. Khim., 31, 227 (1957)

40) Nielsen, R. L. and Weber, J. H. . J. Chem. Eng. Data, 4, 145 (1959)

41) Othmer, D. F. and Benenati, R. F. . Ind. Eng. Chem., 37, 299 (1945)

42) Othmer, D. F. and Josefowitz, S. . Ind. Eng. Chem., 39, 1175 (1947)

43) Othmer, D. F, and Savitt, S. A. - Ind. Eng. Chem., 40, 168 (1948)

44) Othmer, D. F., Shlechter, N. and Koszalka, W. A. . Ind. Eng. Chem., 37, 895 (1945)
45) Othmer, D. F., Silvis, S. J. and Spiel, A. : Ind. Eng. Chem., 44, 1864 (1952)

46) Rasmussen, R. R. and van Winkle, M. . Ind. Eng. Chem., 42, 2121 (1950)

47) Rhodes, F. H., Wells, J. H. and Murray, G. W. . Ind. Eng. Chem., 17, 1199 (1925)

48) Rick, J., Fried, V., Hala, E. and Vilim, O.: Chem. Listy, 47, 1663 (1953)

49) Robinson, C. S. and Gilliland, E. R. : "Elements of Fractional Distillation," 4 th ed. (1950)

50) Rose, A., Acciarri, J. A. and Williams, E. T. : Ind. Eng. Chem., Data Series, 3, 210 (1958)

51) Rose, A., Papahronis, B. T. and Williams, E. T. Ind. Eng. Chem., Data Series, 3, 216 (1958)

52) Savitt, S. A. and Othmer, D. F.: Div. Ind. Eng. Chem., A. C. S. Meeting (1948)

53) Sheinker, Y. N. and Peresleni, E. M. . Zhur. Fiz. Khim., 26, 1103 (1952)

54) Sieg, L. . Chem. Ing. Tech., 22, 322 (1950)

55) Soong, C. C. and Chow, C. S. : Science Record (China), 3, 197 (1950)

56) Struck, R. T. and Kinney, C. R. . Ind, Eng. Chem., 42, 77 (1950)

57) Vilim, O., Hala, E., Fried, V. and Pick, P. . Chem. Listy, 48, 1109 (1954)

58) Ward, S. H. and van Winkle, M. . Ind. Eng. Chem., 16, 338 (1954)

59) Weber, J. H. : Ind. Eng. Chem., 47, 454 (1955)

60) White, W. S. and van Winkle, M. . Ind. Eng. Chem., 46. 1284 (1954)

61) Williams, F. C. and Osburn, J. O.: J. Am. Oil Chemists' Soc., 26, 663 (1949)

62) Wilson, A. and Simons, E. L. . Ind. Eng. Chem., 44, 2214 (1952)

63) Wingard, R. E. and Durant, D. S. : J. Alabama Acad. Sci., 27, 11 (1955)

64) Yang, C. P. and van Winkle, M. . Ind. Eng. Chem., 47, 293 (1955)

65) Zuiderweg, F. J. . Chem. Eng. Sci., 1, 164 (1952)

\section{新刊書紹介}

\section{単位操作演習 \\ 化学エ学シリーズ 别冊 418 頁 \\ 執筆者 藤田 重交 (監修) 早川 豊彦・平田 光穗・榉積 彦二・井上一郎 伊藤 四郎·大竹 伝雄. 白井 隆 \\ 科学技術社 発行}

今は昔の思い出になるが本書の著者の一人から“そ5 たなあ，その場合の伝熱係数は200ぐらいじゃないな あ”といわれて当時の応化出身の小生はふ5んそ5い5 むのかなと感心したことがある。序交にもあるよ5に, 数学，物理，化学を実際問題にどう応用すればよいかを 単位操作という考え方をと扎して演習問題を解くことに よって十分に理解することは工学的センスを養うために きわめて奻果的なことであり，本書はそのよ5な目的で 書かれたものである。内容は

単位の換算，次元解析，流体の流れ，粒子の運動，粒 子群と粒体，等移動，蒸発，物質移動，蒸溜，ガス吸収， 液液抽出, 調湿, 乾燥, 粉磁, 摚拌, 集蚍, 沈降分離,
沪過。

と単位操作の全般にわたりとくに基碟的な事柄が親切 に書かれてあり，化学工学を駆使できる水準に羊するた めの息の切れる厄介な峠を手をとって越えさせてくれる と思5。しかし，この，単位操作で一其した化学工学の 懐しき良きハードコフをマスタするためには計算尺を手 にとって計算をしてみることが必要であるが，本書の演 習問題には全部解答が付してあり，評策尺を使ってみる 䙲気を与寺てくれる。解答を付するという，表面には出 ない努力は評価したい。380頁という手頃な頁数は何よ りも魅力があって，これがまた，必然的に全体を充分に はカパーできない理由とるなっている。（宮内） 